\title{
Interdisciplinary Comparison of Innovation Processes - Differences, Similarities and Spillovers
}

\author{
Michael Filzmoser \\ Institute of Management Science, Vienna University of Technology, Vienna, Austria
}

\begin{abstract}
Innovation processes are of tremendous importance for economic development as they transform new ideas into products and services from which society can benefit. Different industries developed and further-developed unique innovation processes optimally fitting their specific demands. However, several aspects are be relevant to other industries, too, and their imitation could enable innovation process improvements. In this paper we perform an interdisciplinary comparison of innovation processes to identify such general tendencies as well as novel aspects that could spill over to other industries' innovation processes.
\end{abstract}

Keywords: Innovation, Innovation process, Interdisciplinary comparison

\section{Introduction}

Innovation is of tremendous importance for the prosperity and economic development of companies and society likewise. Unless new ideas and inventions are transformed into products and services that better fulfil customer requirements, they generate no benefits for the society. New inputs and processes applied in production improve efficiency and sustainability of companies and likely also yield positive externalities to society and environment. Innovation processes receive great attention in many industries - like the building industry, software engineering or mechanical engineering. What is surprising, however, is that these different industries further-develop innovation processes without much exchange. This exchange between different industries concerning their approaches to transform ideas into products can be expected to be highly valuable. It can provide innovative inputs and advantageous process characteristics from related processes of different industries that are similar enough to learn from them but at the same time different enough to gain novel insights.

This paper makes a first attempt to address this lack of interdisciplinary comparison of innovation processes. We evaluate the innovation processes in new product development of mechanical engineering, building planning and software engineering based on existent literature and models. This endeavour is undertaken to address the research questions whether innovation processes exhibit common developments and allow imitation of advantageous characteristics. The remainder of this paper is structured as follows: Section 2 discusses innovation processes of different disciplines, Sections 3 and 4 focus on similar developments in different industries, i.e. the integration of activities (Section 3) as well as the opening of the innovation process (Section 4). Section 5 concludes the paper and discusses areas of future research.

\section{Innovation Process}

In many domains innovation means bringing launching new products or services at target markets. New product development therefore is an important innovation process. There is no common understanding and definition of the new product development process in general but several models explain its phases, activities and succession of the later (e.g. Thom, 1980, Witt, 1996, Pleschak and Sabisch, 1996, Brockhoff, 1998). Figure 1 provides an overview in form of a compendium of the relevant literature. In general the new product development process can be separated in three distinct phases: (i) the creative phase, (ii) the planning phase, and (iii) the realization phase. 


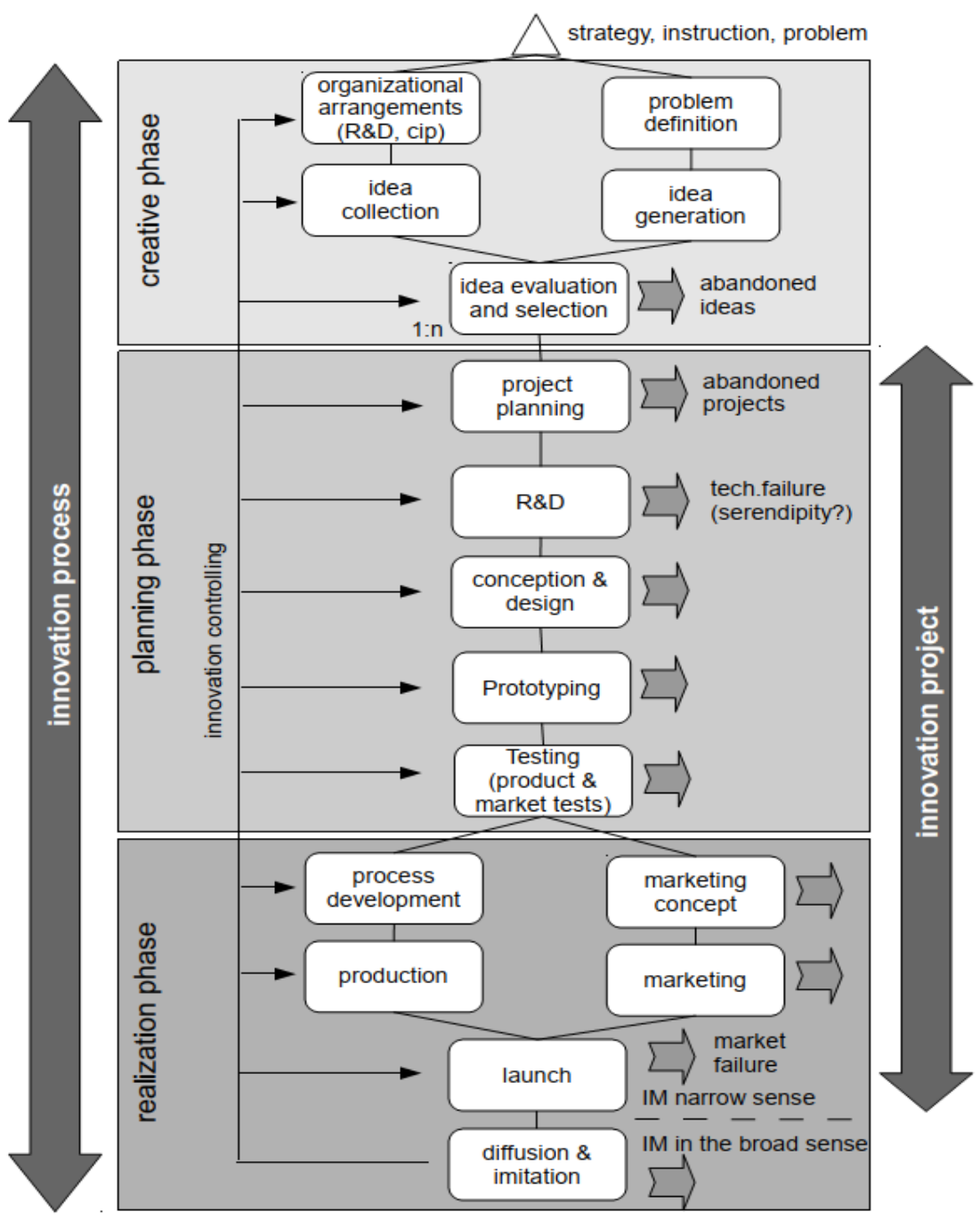

Figure 1: Generic innovation process

The innovation process is triggered by some existing problem or based on an order. The creative phase involves gathering ideas and idea evaluation. Idea gathering can take the form of collecting existing ideas - provided the organizational arrangements like internal suggestion systems, quality cycles etc. are established - or the installation of creative teams to solve the problem at hand. Both variants together or on their own will result in a set of ideas that have to be evaluated. From this evaluation one or several competing innovation projects might emerge, which constitutes the end of the creative phase. In the planning phase the project management for a specific innovation project is accomplished (goals setting, scheduling, etc.) followed by R\&D and conceptual and detailed design. The resulting design is realized in form of prototypes and tested concerning feasibility, efficient producibility and market acceptance. A successful prototype testing initiates the realization phase which involves the development of production processes and marketing strategies as well as their execution and the launch of the product or service at the market - in some cases at test markets followed by a roll-out in case of success.

The market launch of a product ends the innovation project. Innovation management in a broader sense, however, also includes the diffusion and the determination of confrontation strategies for activities of competitors - like attempts to imitate the launched products or services. Of course along this innovation process there are exit points for ideas. The innovation process can be seen as a funnel and only a small fraction of initial ideas will result in successfully launched products, some ideas will be abandoned if negatively evaluated and never lead to innovation projects, some projects will be abandoned in the planning phase as not time- or cost-efficient, furthermore there might be technical failures or market failures. Therefore it is necessary that the innovation process as a selection process is organized as efficient as possible to avoid unnecessary efforts on the one hand and enable the transformation of ideas to products for the benefit of the company and society on the other hand.

The above described generic innovation process, in this form, is applicable for a very relevant but also specific type of new product development, i.e. the technology-driven push innovations rather than the market-driven pull innovation (von Hippel, 1978). Market-driven innovations, but also architecture and construction, have a different sequence of 
basically the same activities. In these disciplines market research and requirements engineering would be the initial steps. Software engineering on the other hand develops immaterial products the production process development and production scheduling would be redundant activities. Though there are many similarities one can observe discipline specific differences in the innovation processes that result from the specific characteristics of the underlying products and services. However, we are on the one hand interested in those differences which cannot be assigned to differences in product characteristics but result from myopic path dependent historical developments and therefore could be, informed by characteristics from other disciplines, altered to further develop innovation processes. On the other hand we are looking for common characteristics in innovation processes that could be integrated in the processes of other disciplines. The subsequent sections will address two such common phenomena, i.e. the integration of innovation activities and the opening of the innovation process.

\section{Integration of Activities}

One phenomenon which can be observed especially in new product development is the integration of innovation process activities. The development was a stepwise starting from sequential processes, where subsequent activities start only after previous activities have been finished, and over time developing to simultaneous processes with overlapping and interconnected activities as illustrated in Figure 2 (Rothwell, 1995, Yazdani and Holmes, 1999).

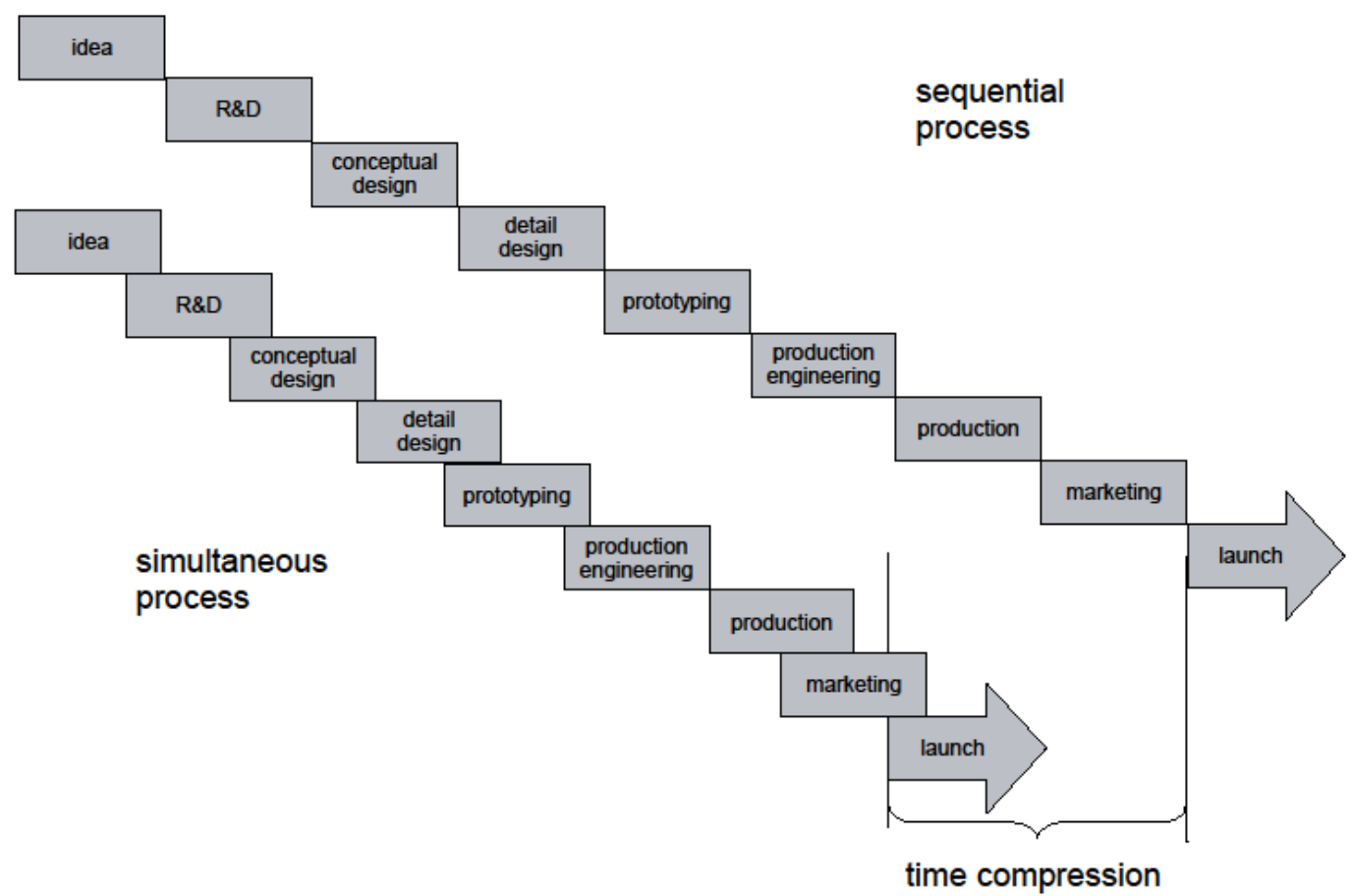

Figure 2: Sequential and simultaneous process (Yazdani \& Holmes 1999)

This change enabled a time compression of the new product development process as well as a better information exchange between different process workers and therefore a considerable improvement in one of the key performance indicators of innovation processes i.e. the time-to-market. The Stage-Gate process (Cooper ,1990) is an example of a sequential innovation processes while concurrent engineering is a simultaneous process. Integrated innovation processes are performed by cross functional teams that cooperate throughout the entire product development process (see Figure 3). This allows for better information exchange between the participants of the different disciplines and avoids time consuming rework loops if later input necessitates adoptions of work undertaken in previous phases, e.g. if customer requirements provided by marketing experts are not considered in the design phase of product development. 


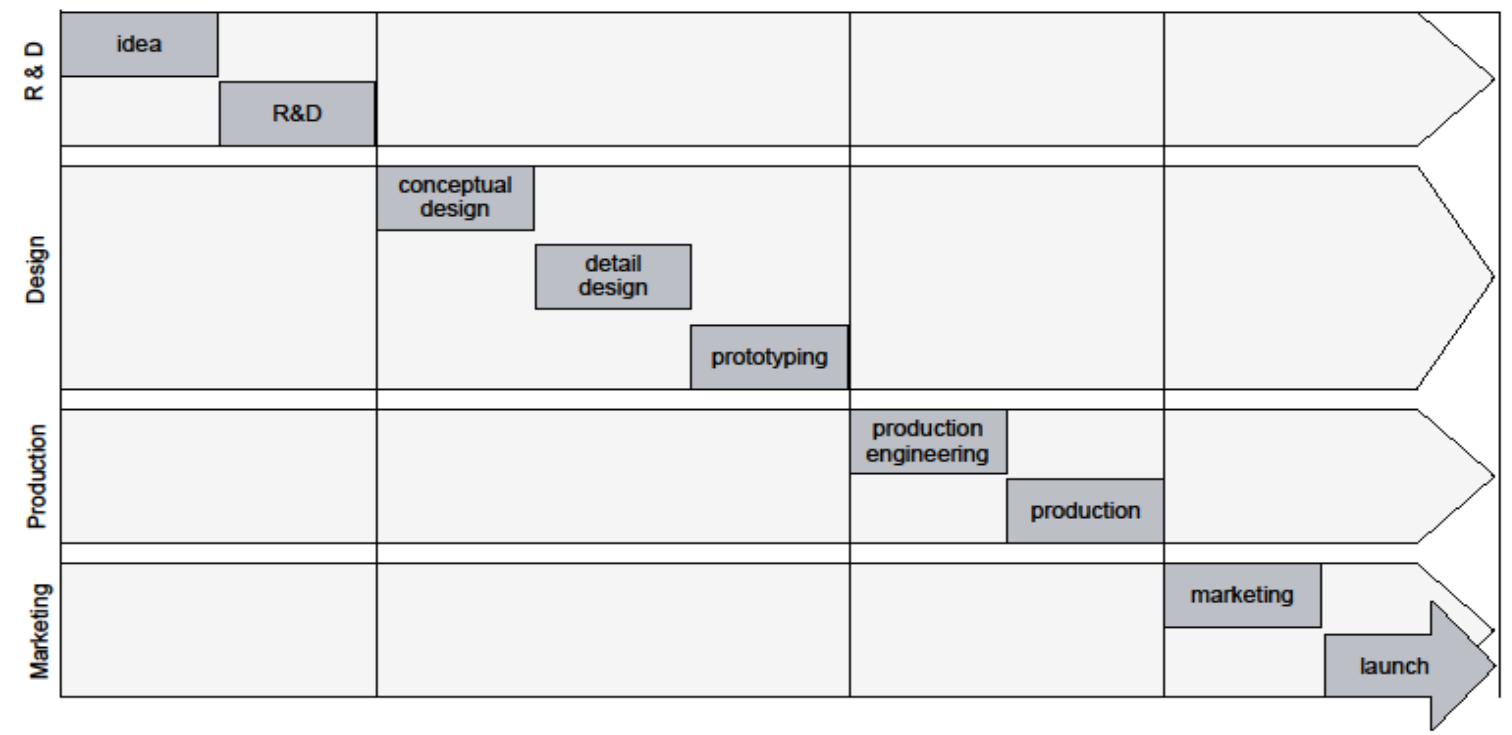

Figure 3: Integrated innovation process

But the integration of activities in the innovation process can also be observed in recent developments of the building planning processes. In building planning this change is performed by a close cooperation of architecture - responsible for the architectural design -, civil engineering - responsible for statics and construction - and building technology responsible for heating, ventilation and air conditioning (HVAC). These roles traditionally worked together in building planning in a sequential manner. The building technology was only considered after civil engineers performed their tasks based on the architectural design provided by architects. Building requirements in terms of energy efficiency, lifecycle costs etc. make building planning much more complex and demand an integrated planning process (Kovacic et al., 2001). This integrated planning is often accompanied by work on a common building model - building information modelling (BIM) - with interoperable design software which is also a relatively new development and recent challenge in this discipline. Similar developments can be observed in software engineering where traditional sequential software development model like the waterfall-model or the V-model where replaced by iterative models like SCRUM.

\section{Opening the Process}

Besides the integration of activities in innovation processes the opening of these processes to participants outside the focal company is another observable development. This phenomenon can be observed in open source software development processes and also in product development, where for instance the users can be integrated in the innovation processes by lead user methods (von Hippel, 1989) or participatory design techniques, but is still missing to a large extent in building planning.

Closed innovation process

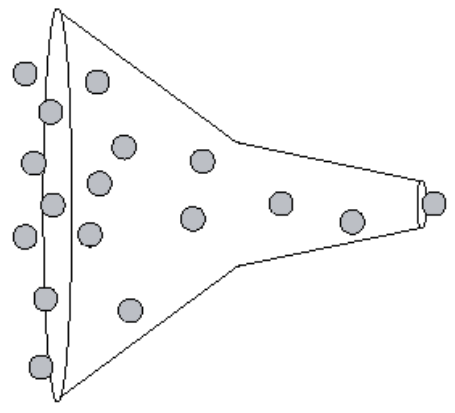

Chesbrough (2006)

Gassmann \& Enkel (2004)

\section{Open innovation process}

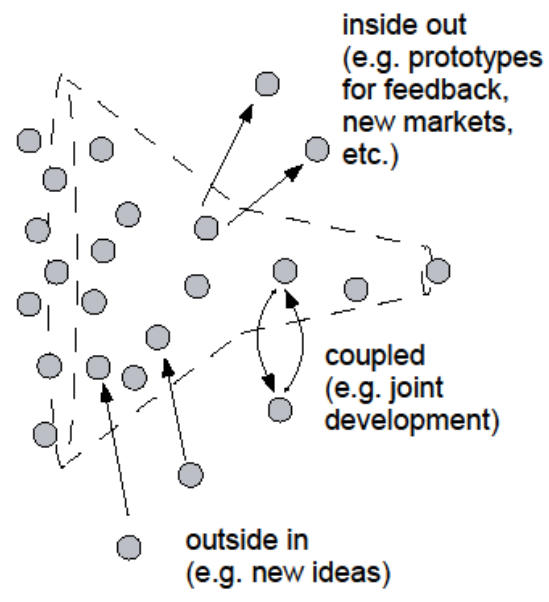

Figure 4: Open innovation (adapted from Gassmann \& Enkel, 2006) 
Such an open innovation process (Chesbrough, 2006) can have multiple forms depending on which actors are integrated at which phases of the innovation process (see Figure 4). New ideas can come from outside the company, for example by means of idea crowdsourcing platforms but also from inside the company and innovation process out for example to receive feedback on prototypes or test new markets. A further possibility is the interactive cooperation with actors outside the company like lead users or even competitors in joint development projects. This opening of the innovation process is not limited to human actors but also includes artificial entities e.g. machine invention systems (Vasilescu and Filzmoser, 2020) in which AI algorithms based on machine learning could develop suggestions for innovations which are evaluated and prioritized by humans. This way, complementary human and artificial actors in such a hybrid socio-technical system could focus on their core competences and realize synergies (Filzmoser and Koeszegi, 2018).

\section{Conclusion}

In this paper we performed a first interdisciplinary comparison of innovation processes. This research was inspired by the idea to enable companies to improve their procedures by imitating superior designs from other industries. This in turn should allow companies be more successful in diffusing novel ideas and technological invention to society. Despite the disciplinary differences the general innovation processes have many aspects, like central activities and their succession, in common and observe - though with different intensity and at different points in time - very similar developments. The parallelization of activities or the opening of the process to external participants - like suppliers, customers, or even competitors - being only two examples of such shared developments. The reasons for these developments can be found in the increasing complexity of products and changes of the competitive environment of innovating companies. Increased complexity of goods and services leads to reciprocal rather than pooled or sequential interdependencies of activities (Thompson, 1976) which calls for integrated innovation processes to cope with this complexity.

The golden triangle of project and process performance, i.e. costs, quality and time, can be operationalized for innovation processes as: (i) development costs, (ii) product quality, i.e. the fulfilment of user requirements and (iii) time-tomarket. In the present innovation competition (Cooper, 2001) time-to-market and product quality become the major issues so that higher cost innovation processes based on integrated or simultaneous activities are preferable alternatives as they have the potential to reduce time-to-market and increase the quality of the outcome of innovation processes. This emphasize of high quality of developed products in innovation processes by means of optimally fitting user requirements to a large extend also explains the opening of innovation processes, besides the novel ideas open innovation approaches can result in.

However, these similar developments are not observed in all industries, i.e. the opening of the innovation process is something more often found in software engineering and new product development processes in mechanical engineering but not in building development processes. Furthermore, the integration of activities of different participants in the innovation process were considered in building engineering - by the development of integrated building planning and building information modelling - only recently and are a current topic in this discipline, while they more established in other disciplines like product development or software engineering. Therefore, there seems to be considerable potential to imitate innovation process characteristics across industries in attempt to learn from each other. To enable exchange and further-development of innovation processes it is necessary that future research systematically compares them across the different disciplines. This requires in a first step to identify innovation processes of different industries. In this context it would be interesting to include industries less involved in engineering and manufacturing, like industries from the service sector, to gain an even broader understanding of innovation activities. These innovation processes in a second step have to be modelled uniformly to enable interdisciplinary comparisons. Based on these models we could examine commonalities and domain specific differences. Moreover from the development of innovation processes in different industries over time, general tendencies that affect them can be observed, as well as novel aspects that could spill over to other industries' innovation processes. Another promising area of future research is the application to general process theory to improve innovation processes (Harrington, 1991, Kettinger et al., 1997, Österle, 1995) and to analyse and imitate other operative business processes to derive improvements for innovation processes (Haradon, 2003).

Acknowledgement: A previous version of this paper was presented at 6th International Scientific Conference on Economic and Social Development, Vienna, Austria, the valuable feedback from the participants is gratefully acknowledged. 


\section{References}

- Brockhoff, K. (1998) Forschung und Entwicklung, 5th ed, München, Oldenbourg. CrossRef

- Chesbrough, H. (2006) Open Innovation: The New Imperative for Creating and Profiting from Technology. Boston: Harvard Business School Press. $\underline{\text { CrossRef }}$

- Cooper, R.G. (1990) Stage-Gate Systems: A New Tool for Managing New Products, Business Horizons, MayJune. CrossRef

- Cooper, R.G. (2001) Winning at new Products: Accelerating the Process from Idea to Launch, Cambridge, Perseus Books. CrossRef

- Filzmoser, M. and Koeszegi, S.T. (2018) Integrating robotics and artificial intelligence in business processes - An organization theoretical analysis, Frontiers in Artificial Intelligence and Applications. CrossRef

- Gassmann, O. and Enkel, E. (2006) Open Innovation: Externe Hebeleffekte in der Innovation erzielen, Zeitschrift Führung + Organisation. CrossRef

- Haradon, A. (2003) How breakthroughs happen. The surprising Truth about how companies innovate. Boston, Harvard Business School Press. CrossRef

- Harrington, H.J. (1991) Business Process Improvement. New York, McGraw-Hill. CrossRef

- Kettinger, W.J., Teng, J.T.C. and Guha, S. (1997) Business process change: A study of methodologies, techniques, and tools, MIS Quarterly. CrossRef

- Kovacic, I., Filzmoser, M., Faatz, S. and Koeszegi, S.T. (2011) Costs and benefits of integrated planning: First experiment results, Organization Technology and Management in Construction. CrossRef

- Österle, H. (1995): Business Engineering. Heidelberg, Springer. CrossRef

- Pleschak, F. and Sabisch, H. (1996) Innovationsmanagement, Stuttgart, Schäffer-Poeschel. CrossRef

- Rothwell, R. (1995) The fifth generation innovation process, in: Oppenländer, K.H. and Popp, W. (eds) Innovationen und wirtschaftlicher Fortschritt. Bern, Haupt. CrossRef

- Thom, N. (1980) Grundlagen des betrieblichen Innovationsmanagements, 2nd ed, Königstein, Hanstein. CrossRef

- Tompson, J.D. (1976) Organizations in Action: Social Science Bases of Administrative Theory, New-York, McGraw-Hill. CrossRef

- Vasilescu, D.C. and Filzmoser, M. (2020) Machine invention systems: A (r)evolution of the invention process? AI $\&$ Society, forthcoming. CrossRef

- $\quad$ von Hippel, E.A. (1978) Successful Industrial Products from Customer Ideas, Journal of Marketing. CrossRef

- $\quad$ von Hippel, E.A. (1989) New product ideas from lead users, Research Technology Management. CrossRef

- Witt, J. (1996) Produktinnovation, München, Vahlen. CrossRef

- Yazdani, B. and Holmes, C. (1999) Four models of design definition: Sequential, design centred, concurrent and dynamic, Journal of Engineering Design. $\underline{\text { CrossRef }}$ 